\title{
Comparison of seroconversion rates between low-dose intradermal and recommended dose intramuscular hepatitis $B$ vaccination in children
}

\author{
Sony HA Harsono, MD; Zarkasih Anwar, MD; Nancy Pardede, MD
}

\begin{abstract}
Introduction Massive hepatitis B vaccination is expensive. Results of studies showed that reduced dosage given intradermally to adults and intramuscularly to children were able to induce seroconversion.

Objective To compare the anti-HBs seroconversion (seropositive and seroprotective) rates between intradermal low-dose of $2 \mathrm{mg}$ (ID-2) and intramuscular recommended dose of $10 \mathrm{mg}$ (IM-10) vaccination against hepatitis $B$.

Methods In a randomized clinical trial, using the hepatitis $B$ plasma vaccine, elementary school children in Tanjung Enim subdistrict, 80-168 months of age, were randomly assigned to be given three doses of either the ID-2 $(n=59)$ or IM-10 $(n=64)$ vaccinations at one month intervals. Seropositive (anti HBs titer $\geq 2.1 \mathrm{mIU} / \mathrm{l}$ ) and seroprotective (anti HBs $\geq 10 \mathrm{mIU} / \mathrm{l}$ ) rates as well as the seropositive and seroprotective geometric mean antibody titers (GMTs) were compared one month after each inoculation. A p value of $<0.1$ was considered statistically significant.

Results One month after the third inoculation, there was no significant difference in the seropositive rate (95\% vs. $89 \%)$, seroprotective rate ( $85 \%$ vs. $83 \%$ ), seropositive GMTs ( $55.85 \mathrm{mlU} /$ I vs. $61.24 \mathrm{mIU} / \mathrm{l})$, and seroprotective GMTs $(73.86 \mathrm{mIU} / \mathrm{l}$ vs. 72.49 $\mathrm{mIU} / \mathrm{I}$ ) between the ID-2 and the IM-10 groups (all with $\mathrm{p}>0.1$ )

Conclusion Reduced doses of the hepatitis $B$ vaccine given intradermally may offer protection against hepatitis $B$, thus it may be useful for mass vaccination programs [Paediatr Indones 2003;43:140-146].
\end{abstract}

Keywords: Hepatitis B vaccination, intradermal, intramuscular, seroconversion

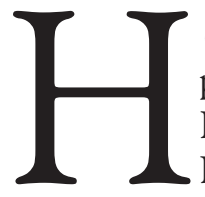

epatitis-B is a serious public health problem in many countries including in Indonesia. The prevalence of HepatitisB Surface Antigen ( $\mathrm{HbsAg})$ in Indonesia ranges between $2.5-36.17 \%$ in children. According to the $\mathrm{WHO}$ criteria, Indonesia is classified as a region with moderate to high endemicity, therefore, preventive and eradicative measures for HBV are highly recommended. ${ }^{1-4}$ Owing to the high cost of the hepatitis vaccine, massive hepatitis $B$ vaccination is expensive. There is a need to find an alternative way to use the hepatitis B vaccine efficiently and effectively by reducing vaccine doses and thus, cost.

Studies showed that reduced dose of hepatitis B vaccine given intradermally was as effective as the intramuscularly given recommended dose with regard to the seroconversion rate, anti-HBs titers, and the peak geometric mean titers (GMT). ${ }^{5-12}$ All of these studies dealt with adult subjects. Studies conducted in Africa and the Far East showed that reduced dosages of hepatitis vaccine were able to induce seroconversion in children. The vaccine in these studies, however, was given intramuscularly. ${ }^{13}$ The purpose of our study was to compare the anti-HBs seroconversion rates: seropositive anti-HBs titers, seroproctective anti-HBs titers, and seropositive as

From the Department of Child Health, Medical School, Sriwijaya University, Mohammad Hoesin Hospital, Palembang.

Request reprints to: Zarkasih Anwar, MD, Department of Child Health, Medical School, Sriwijaya University, Mohammad Hoesin Hospital, Palembang, Indonesia. Tel. 62-711-354088, Fax.62-711-372832.

Presented at the Indonesian Society of Pediatricians $1^{\text {st }}$ Annual Scientific Meeting in Palembang, July 27-29, 2001. 
well as seroprotective GMTs between low-dose (2 $\mathrm{mg}$ ) intradermal (ID-2) and recommended dose (10 $\mathrm{mg}$ ) intramuscular (IM-10) hepatitis $B$ vaccination in schoolchildren. It was hoped that the results of this study could be used as an alternative method to reduce the cost and dose of the vaccination, so that extensive protection against the danger of HBV infection in children can be achieved.

\section{Methods}

A prospective experimental, randomized clinical trial was designed to compare the results of a low dose intradermal (ID -2) and a recommended dose intramuscular (IM-10) vaccination schedule. Subjects were students from 3 elementary schools randomly selected from 31 elementary schools in Tanjung Enim Subdistrict - South Sumatera.

Based on the estimation that $88 \%$ of the subjects in the ID-2 group and $98 \%$ in the IM-10 group will become seropositive with $\mathrm{a}=0.1$ and a power of $80 \%$, and considering a drop out rate of $10 \%$, the required sample size was 55 for each group. Based on the estimation that $80 \%$ of the subjects in the ID-2 group and $95 \%$ in the IM-10 group would develop seroprotective anti-HBs titers, with $\mathrm{a}=0.1$ and $\mathrm{a}$ power of $80 \%$, and considering a drop out rate of $10 \%$, the required sample size was 44 for each group. So we decided to recruit minimally 55 children in each group.

Subjects should fulfill the following inclusion criteria: healthy, never been vaccinated with HBV, agreed to participate, and had to be negative for $\mathrm{HbsAg}$, anti HBs, and Anti $\mathrm{HBc}$ examinations mea- sured by Enzyme-Linked Immunosorbent Assay (ELISA) using the diagnostic Kit form Organon Teknika. They were then randomly allocated into 2 groups: the ID-2 and IM-10 group. Children were excluded from the study if throughout the study period an allergic reaction developed, immunosuppressive drugs were used, became ill frequently, or did not complete the whole vaccination schedule.

The vaccine used was a plasma derived vaccine (Hepa B $1 \mathrm{ml}=20 \mathrm{mg}$ ) produced by The Korean Green Cross Corporation; batch no. 1330-400-55-2/ 1331-400-55-2. The ID-2 group received $0.1 \mathrm{ml}(2 \mathrm{mg})$ of the vaccine, injected intradermally on the deltoid region of the right limb using a tuberculin/insulin syringe with a no. $27 \mathrm{G}$ needle. The IM- 10 group received $0.5 \mathrm{ml}(10 \mathrm{mg})$ of the vaccine, injected intramuscularly on the deltoid region of the left limb using a tuberculin/insulin syringe with a no. $23 \mathrm{G}$ needle. Three doses of the vaccine were inoculated at monthly intervals (month $0,1,2$ ). The children were provided with an identity card including the next vaccination date and a space to record any complaints or side effects associated with each inoculation. Anti-HBs titers were examined every one month after each inoculation.

Data were processed using the Epi info 6 computer software program. Seropositive and seroprotective rates were analyzed using the Chi-Square test whereas seropositive/seroprotective anti-HBs titers and seropositive/seroprotective GMTs were analyzed using the Student's t-test. The GMTs were calculated by taking the log of the antibody concentrations and then taking the antilog of the means of these values. A $p$ value of $<0.1$ was considered statistically significant.

Table 1. General characteristics of SubJects in the ID-2 and IM-10 Groups

\begin{tabular}{|c|c|c|c|c|}
\hline $\begin{array}{l}\text { Subject } \\
\text { Characteristics }\end{array}$ & $\begin{array}{l}\text { IM-10 Group } \\
\mathrm{n}=64\end{array}$ & $\begin{array}{l}\text { 'ID-2 Group } \\
\mathrm{n}=59\end{array}$ & $\begin{array}{l}\text { Total } \\
(\%)\end{array}$ & $p$ \\
\hline \multicolumn{5}{|l|}{ 1. Age (months) } \\
\hline $80-120$ & 43 & 46 & $89(72)$ & $0.257 @$ \\
\hline $121-168$ & 21 & 13 & $34(23)$ & \\
\hline Mean age & $117.39+19.4$ & $111.83+13.1$ & & $0.177^{\star}$ \\
\hline \multicolumn{5}{|l|}{ 2. Sex } \\
\hline Male & 32 & 26 & $58(47)$ & 0.633@ \\
\hline Female & 32 & 33 & $65(43)$ & \\
\hline \multicolumn{5}{|l|}{ 3. Nutritional status } \\
\hline Moderate & 12 & 8 & $20(16)$ & 0.450@ \\
\hline Good & 52 & 51 & $103(84)$ & \\
\hline
\end{tabular}


Table 2. Seropositive rates and seropositive anti-HBs titers 1 month after the $1^{\text {st }}$, $2^{\mathrm{ND}}$ AND $3^{\mathrm{RD}}$ INOCULATIONS

\begin{tabular}{lcc}
\hline $\begin{array}{l}\text { Seroconversion of } \\
\text { Anti-HBs titer (mIU/mI) }\end{array}$ & $\begin{array}{c}\text { IM-10 Group } \\
\mathbf{n}=\mathbf{6 4} \\
(\%)\end{array}$ & $\begin{array}{c}\text { ID-2 Group } \\
\mathbf{n}=59 \\
(\%)\end{array}$ \\
\hline 1 month post $1^{\text {st }}$ inoculation & & \\
$0.0-2.1$ & $36(56)$ & $38(64)$ \\
$>2.1-9.9$ & $2(3)$ & $1(2)$ \\
$10.0-49.9$ & $23(36)$ & $17(29)$ \\
$50.0-100.0$ & $1(2)$ & $2(3)$ \\
$>100.0$ & $2(3)$ & $1(2)$ \\
& & \\
1 month post $2^{\text {nd }}$ inoculation & $14(22)$ & $9(15)$ \\
$0.0-2.1$ & $2(3)$ & $4(7)$ \\
$>2.1-9.9$ & $14(22)$ & $11(19)$ \\
$10.0-49.9$ & $27(42)$ & $27(46)$ \\
$50.0-100.0$ & $7(11)$ & $8(14)$ \\
$>100.0$ & & \\
& & $3(5)$ \\
1 month post $3^{\text {rd } \text { inoculation }}$ & $7(11)$ & $6(10)$ \\
$0.0-2.1$ & $4(6)$ & $10(17)$ \\
$>2.1-9.9$ & $12(19)$ & $7(12)$ \\
$10.0-49.9$ & $4(6)$ & $33(56)$ \\
$50.0-100.0$ & $37(58)$ & \\
$>100.0$ & &
\end{tabular}

Seroconversion was regarded as seropositive if the anti-HBs titer was $>2.1 \mathrm{mIU} / \mathrm{ml}$ and seroprotective if the anti-HBs titer was $\geq 10 \mathrm{mIU} / \mathrm{ml}$.

Subjects were considered as healthy if the weight for height was between P3-P97 of the standard according to KMS Anak Sekolah Dep.Kes, 1996 and if during the study, temperature never exceeded $38.5^{\circ} \mathrm{C}$.

\section{Results}

The study was conducted from April-August 1999, involving students from class III-V Elementary School No. I, III, and VI. Out of 152 children selected randomly, 29 were excluded from the analysis: 7 with positive anti-HBs; 2 with positive anti-HBs and anti$\mathrm{HBc} ; 2$ with positive $\mathrm{Hbs} \mathrm{Ag}$; and 18 did not complete the vaccination schedule.

One hundred and twenty three children who fulfilled the study criteria were randomized according to their registration: children with odd numbers were recruited in the ID-2 group whereas those with even numbers in the IM-10 group. There were 59 children recruited in the ID- 2 group and 64 in the IM-10 group.

Table 1 shows the characteristics of the subjects. Generally, there was no statistical significant difference between the two groups.
Table 2 shows the positive seroconversion (seropositive) rate and seropositive titers of antiHBs in the two study groups, examined every one month after the $1^{\text {st }}, 2^{\text {nd }}$, and 3 rd inoculations.

One month after the $3^{\text {rd }}$ inoculation, in the IM-10 group, 7 children $(11 \%)$ were seronegative (anti-HBs titer $<2.1 \mathrm{mIU} / \mathrm{ml})$ whereas $57(89 \%)$ were seropositive, with 53 among them (83\%) possessing seroprotective titers $(>10 \mathrm{mIU} / \mathrm{ml})$ and out of these, 37 (70\%) had anti-HBs titers of more than $100 \mathrm{mIU} / \mathrm{ml}$. In the ID-2 group, 3 children (5\%) were seronegative whereas 56 (95\%) were seropositive, with 50 among them $(85 \%)$ possessing seroprotective titers, and out of these, 33 (66\%) had anti-HBs titers of more than $100 \mathrm{mIU} / \mathrm{ml}$.

The percentage of seropositive children, the mean seropositive anti-HBs titers, and the seropositive GMTs in the ID-2 and IM-2 groups one month after the $1^{\text {st }}, 2^{\text {nd }}$ and, $3^{\text {rd }}$ inoculations are shown in Table 3 and Figures 1 and 2.

Figure 2 shows that the ID- 2 group had a higher seropositive rate (95\%) compared to the IM-10 group (89\%), although the difference was not statistically significant. Figure 3 shows that intradermal injections were followed by a more accelerated immune response compared to the intramuscular injections, as shown by the higher seropositive GMTs after the $2^{\text {nd }}$ inoculation $(53.21 \mathrm{mIU} / \mathrm{ml}$ versus $45.92 \mathrm{mIU} / \mathrm{ml})$ but the 
Table 3. Percentage of positive seroconversion, mean seropositive anti-HBs TITERS, AND THE SEROPOSITIVE GMTS IN CHILDREN IN THE ID-10 AND ID-2 GROUPS ONE MONTH AFTER THE $1^{\text {ST }}, 2^{\text {ND }}$, AND $3^{\text {RD }}$ INOCULATIONS.

\begin{tabular}{|c|c|c|c|}
\hline Positive seroconversion & $\begin{array}{l}\text { IM-10 Group } \\
\mathrm{n}=64\end{array}$ & $\begin{array}{l}\text { ID-2 Group } \\
\mathrm{n}=59\end{array}$ & $\mathbf{p}$ \\
\hline \multicolumn{4}{|l|}{1 month post $1^{\text {st }}$ inoculation } \\
\hline Number of children (\%) & $28(44)$ & $21(36)$ & $0.460 @$ \\
\hline Mean anti-HBs titer (mlU/ml) & $27.44 \pm 27.38$ & $26.57+26$ & $0.863 \#$ \\
\hline GMTs (mlU/ml) & $19.77^{-}$ & 19.23 & $0.893 \#$ \\
\hline \multicolumn{4}{|l|}{1 month post $2^{\text {nd }}$ inoculation } \\
\hline Number of children (\%) & $50(78)$ & $50(85)$ & 0.478@ \\
\hline Mean anti HBs titer (mlU/ml) & $62.68 \pm 35.42$ & $72.10 \pm 37.08$ & $0.194 \#$ \\
\hline GMTs (mlU/ml) & 45.92 & 53.21 & $0.541 \#$ \\
\hline \multicolumn{4}{|l|}{1 month post $3^{\text {rd }}$ inoculation } \\
\hline Number of children (\%) & $57(89)$ & $56(95)$ & $0.237 @$ \\
\hline Mean anti-HBs titer (mlU/ml) & $76.94 \pm 34.65$ & $75.69 \pm 36.73$ & $0.847 \$$ \\
\hline GMTs $(\mathrm{mlU} / \mathrm{ml})$ & 61.24 & 55.85 & $0.618 \#$ \\
\hline
\end{tabular}

Note: $@=$ Chi Square test \# = Student's t test $\$=$ Fisher's Exact test

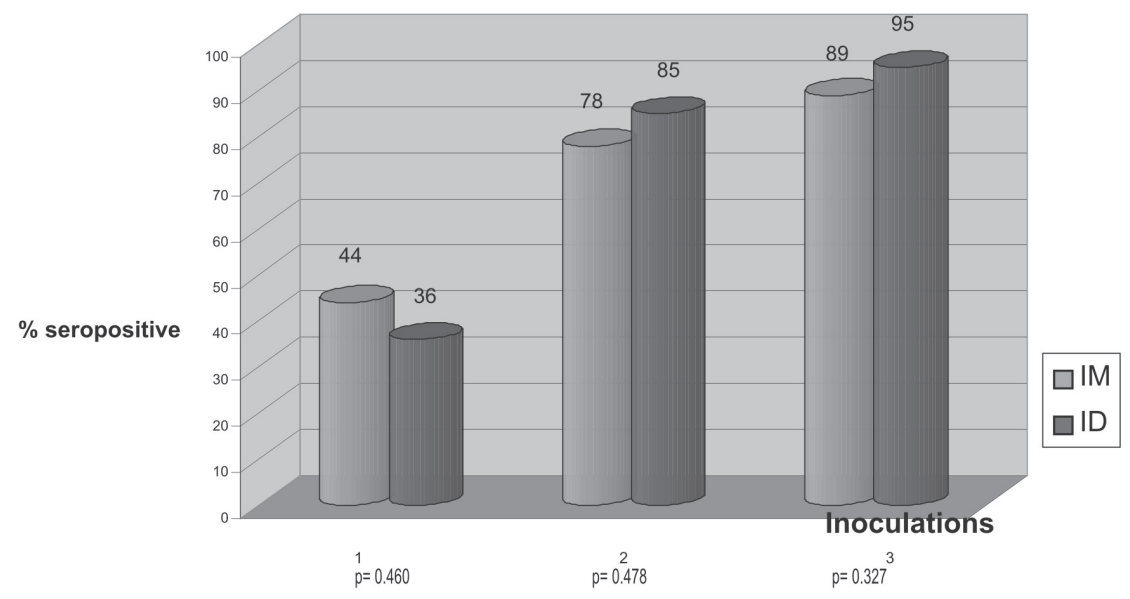

Figure 1. The percentage of children with seropositive anti-HBs titer in the IM-10 and ID-2 groups, 1 month after the 1st, 2nd and 3rd inoculations

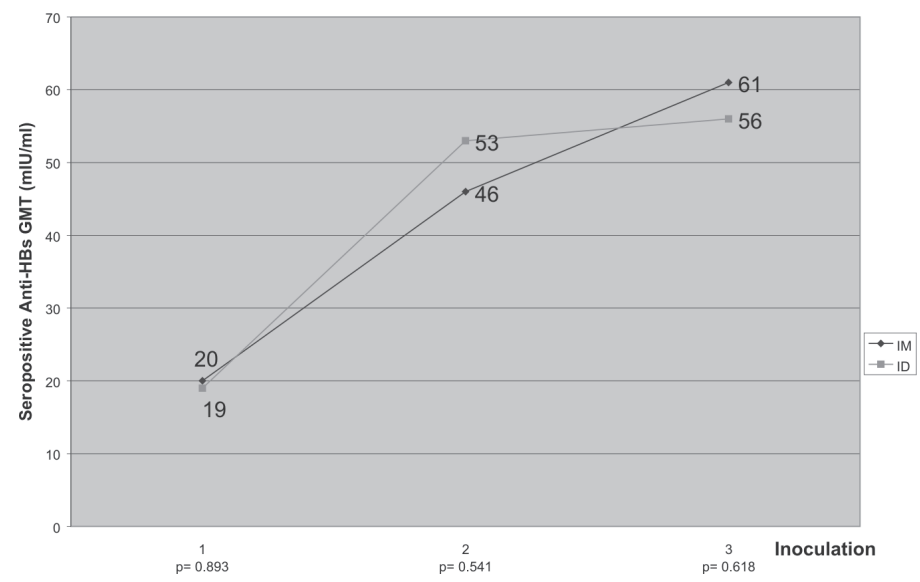

Figure 2. The seropositive anti-HBs GMT values among children in the IM-10 and ID-2 groups, 1 month after the 1st, 2nd and 3rd inoculations 
reverse happened one month after the $3^{\text {rd }}$ inoculation, where the GMTs in the IM-10 group were higher than those in the ID-2 group $(61.24 \mathrm{mIU} / \mathrm{ml}$ versus $55.85 \mathrm{mIU} / \mathrm{ml})$. Although the seropositive GMTs in the IM-10 group, one month after the $3^{\text {rd }}$ inoculation were higher than those in the ID-2 group, the difference was not statistically significant.

The percentage of children with seroprotective anti-HBs titers, mean anti-HBs titers and seroprotective GMTs in the IM-10 and ID-2 groups, 1 month after the $1^{\text {st }}, 2^{\text {nd }}$ and $3^{\text {rd }}$ inoculation are shown in Table 4 and Figures 3 and 4 .
Just like the seropositive rates, mean seropositive anti-HBs titers and seropositive GMTs, the seroprotective rates, mean seroprotective anti-HBs titers, and seroprotective GMTs were higher in the ID-2 group compared to the IM-10 group, although the difference was not statistically significant. Not like the seropositive anti-HBs titers, as seen in Figure 4, the seroprotective anti-HBs titers in the ID-2 group rose rapidly after the $2^{\text {nd }}$ inoculation and remained slightly higher than those of the IM-10 group one month after the $3^{\text {rd }}$ inoculation.

Table 4. Percentage of protective seroconversion, mean seroprotective anti-HBs TITERS AND THE SEROPROTECTIVE GMTS IN CHILDREN IN THE ID-10 AND ID-2 GROUPS ONE

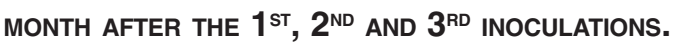

\begin{tabular}{|c|c|c|c|}
\hline $\begin{array}{l}\text { Positive sero- } \\
\text { protection }\end{array}$ & $\begin{array}{l}\text { IM-10 Group } \\
n=64\end{array}$ & $\begin{array}{l}\text { ID-2 Group } \\
n=59\end{array}$ & $\mathbf{p}$ \\
\hline \multicolumn{4}{|l|}{1 month post $1^{\text {st }}$ inoculation } \\
\hline Number of children (\%) & $26(41)$ & $20(34)$ & $0.559 @$ \\
\hline Mean anti-HBs titer (mIU/ml) & $30.67 \pm 28.30$ & $27.05+26.88$ & $0.676 \#$ \\
\hline GMTs (mlU/ml) & $23.25^{-}$ & 20.42 & $0.550 \#$ \\
\hline \multicolumn{4}{|l|}{1 month post $2^{\text {nd }}$ inoculation } \\
\hline Number of children (\%) & $48(75)$ & $46(78)$ & $0.861 @$ \\
\hline Mean anti HBs titer (mlU/ml) & $66.28+33.40$ & $79.34+31.53$ & $0.054 \#$ \\
\hline GMTs $(\mathrm{mlU} / \mathrm{ml})$ & 51.29 & 68.82 & $0.097 \#$ \\
\hline \multicolumn{4}{|l|}{1 month post $3^{\text {rd }}$ inoculation } \\
\hline Number of children (\%) & $53(83)$ & $50(85)$ & $0.964 @$ \\
\hline Mean anti-HBs titer (mlU/ml) & $82.30 \pm 29.63$ & $84.25 \pm 28.56$ & $0.773 \#$ \\
\hline GMTs (mlU/ml) & 72.49 & 73.86 & $0.799 \#$ \\
\hline
\end{tabular}

Note: @= Chi Square test \#=Student's t test

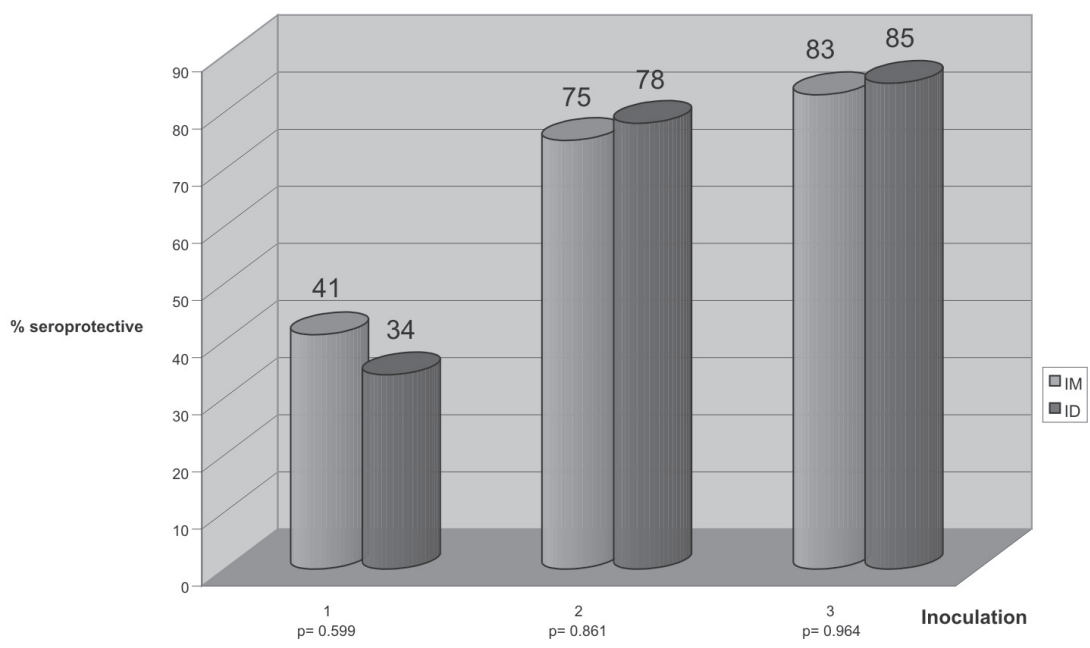

Figure 3. The percentage of children with seroprotective anti-HBs titer in the IM-10 and ID-2 groups 1 month after the 1st, 2nd and 3rd inoculations 
Sony HA Harsono et al: Seroconversion rate of intradermal hepatitis B vaccination

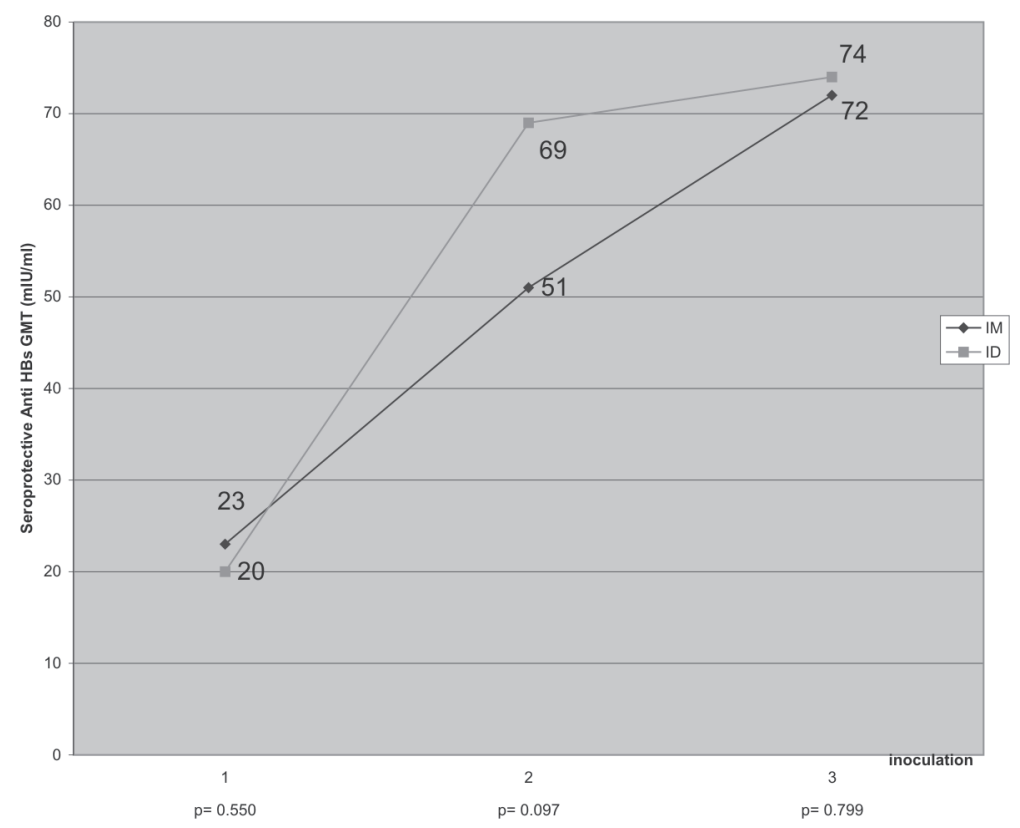

Figure 4: The seroprotective anti-HBs GMT values among children in the IM-10 and ID-2 groups, 1 month after the 1st, 2nd and 3rd inoculations

\section{Discussion}

Previous studies showed that seroconversion after lowdose intradermal injection was $82-100 \%$, similar to that after full dose intramuscular injection. ${ }^{5-13}$ Studies in children conducted in Senegal, Taiwan, and Thailand reported that even at reduced dosages hepatitis $B$ vaccine were able to induce seroconversion in children at rates approaching that of the full dose. These studies, however, did not involve schoolchildren ${ }^{14}$. The Senegal study involved infants between three and five months; the Taiwan study involved preschool children aged between one and seven and the Taiwan study involved neonates. All these studies did not use the intradermal route. ${ }^{14}$

Compared to previous studies ${ }^{6-8,10,12-14}$ our results showed a lower seroprotective mean anti-HBs titer and GMTs either in the ID-2 or IM-10 groups. This may be due to the difference in the laboratory test sensitivity. Most of the other studies used radio immunoassays which are very sensitive compared to the ELISA. This was the limitation of our study since ELISA could only measure anti-HBs titers up to 100 $\mathrm{mIU} / \mathrm{ml}$, while there were 37 children $(58 \%)$ in the IM-10 group and 33 (56\%) in the ID-2 group who had anti-HBs titers $>100 \mathrm{mIU} / \mathrm{ml}$.

The results of this study actually can not be com- pared to other studies because there are many differences amongst them. Subjects in this study were schoolchildren whereas in the other studies, the subjects were adults, ${ }^{6-13}$ although the vaccine was given also intradermally. Other studies on children involved neonates, infants, and preschool children, ${ }^{14}$ but the vaccine was given intramuscularly. We chose older elementary school children (>Class III) because studies with adults reported that younger adult subjects showed better responses compared to older subjects. We thought that maybe this also holds true for older children. The intradermal route was used because of the considerable financial saving of the reduced dosage of intradermal injections; the intradermal route reported being more efficient because Langerhans' cells in the dermis of the skin are more effective at presenting antigen. ${ }^{11}$

There were 11 (17\%) children in the IM-10 group and 9 (15\%) in the ID-2 group who did not possess seroprotective anti-HBs titer. Due to ethical considerations these children will be given another inoculation of the recommended dose intramuscularly.

We concluded that although the difference was not statistically significant, low-dose intradermal injections of hepatitis $B$ vaccines gave better results with regard to seroconversion rates (seropositive and seroprotective), the mean seropositive and seroprotective anti-HBs ti- 
ters, and the seropositive and seroprotective GMTs, compared to intramuscular injections of the recommended dose. Low dose intradermal vaccination can offer protection against hepatitis $B$ infection at rates higher than that of the recommended dose and at a lower cost. Since reduced doses of hepatitis $B$ vaccine given intradermally may offer similar protection against hepatitis B infection, as that of intramuscular recommended dose, this method can be proposed as an alternative for mass vaccination programs.

\section{Acknowledgements}

The authors would like to thank Dr. Zulkarnain, MMed.Sc from The Department of Public Health who assisted with the statistical analyses. We also thank PTBA in Tanjung Enim for providing the vaccines and laboratory facilities.

\section{References}

1. Sulaiman A, Julitasari. Panduan praktis: penatalaksanaan dan pencegahan hepatitis B. $1^{\text {st }}$ ed. Jakarta: Yayasan Penerbitan Ikatan Dokter Indonesia; 1998.

2. Hidayat B. Pemberian vaksin hepatitis B pada anak secara universal. Proceedings of the Symposium on up date of hepatitis B prevention in children; 1993 Aug; p.1-6.

3. Sulaiman A, Julitasari. Virus hepatitis A sampai E di Indonesia. Jakarta: Yayasan Penerbit Ikatan Dokter Indonesia; 1995.p.16-76.

4. Direktorat Jenderal PPM dan PLP Depkes RI. $2^{\text {nd }}$ ed. Petunjuk teknis pelaksanaan imunisasi hepatitis B. Jakarta: Departemen Kesehatan; 1996. p.1-20.

5. Redfield RR, Innis BL, Scott RM, Cannon HG, Bancroft WH. Clinical evaluation of low-dose intrad- ermally administered hepatitis B virus vaccine: a costreduction strategy. JAMA 1985;254:3203-6.

6. Bryan JP, Sjogren MH, Perine PL, Legters LJ. Review articles: low dose intramuscular vaccination against hepatitis B. Clin Infect Dis 1992; 14: 697-707.

7. Wahl M, Hermodsson S. Intradermal, subcutaneous or intramuscular administration of hepatitis B vaccine: side effects, antibody response. Scand J Infect Dis 1987;19:617-21

8. Miller KD, Mulligan MW, Gibbs RD, Hutman TS, Francis DP. Intradermal HBV vaccination: immunogenicity and side effects in adults. Lancet 1983;2:1454-56.

9. Bryan JP, Sjogren M, Igbal M, Khattak AR, Nabi S, Ahmed A, et al. Comparative trial of low-dose, intradermal recombinant and plasma derived hepatitis $B$ vaccines. J Inf Dis 1990;162:789-793.

10. Leonardi S, Musumeci S, Sciacca A, Greco D, Romano C. Reliability of intradermal vaccination against hepatitis B for accelerated prophyalxis. Pediatr Infect Dis 1990;336:520.

11. Thomson SC, Darlington R, Tallent DB, Forsyth JRL. Effectiveness of low dose intradermal hepatitis $B$ vaccination: five years' experience of primary vaccination. Med J Austr 1993;158:372-8.

12. Coleman PJ, Shaw FE, Hadler SC, Margolis HS, Serovich J. Intradermal hepatitis B vaccination in a large hospital employee population. Vaccine 1991;7:58-62.

13. Clark JA, Hollinger FB, Lewis E, Russell LA, Miller $\mathrm{CH}$, Huntley AC, et al. Intradermal inoculation with Heptavax B: immune response and histologic evaluation of injection sites. JAMA 1989;262:2567-71.

14. NN. Low-dose vaccine in children: impressive performance holds promise of cost savings. Hevac Bulletin $1995 ; 3: 1-3$ 